\title{
FURTHER MEASURES OF COMET a 1904 (BROOKS) *
}

The following measures, obtained with the 12-inch refractor, continue* the series published in Lick Observatory Bulletin Number 56. The $\Delta a$ comparisons were all made directly with the micrometer except those of June 21, made by transits. The observations of July 8, August 26 and September 4 were made by Dr. R. G. Aitken.

\begin{tabular}{|c|c|c|c|c|c|c|c|c|c|c|c|c|c|c|c|c|c|c|}
\hline \multirow{2}{*}{\multicolumn{5}{|c|}{ Mt. Hamilton M.T. }} & \multirow{3}{*}{$\begin{array}{l}\text { Star } \\
1\end{array}$} & \multirow{3}{*}{$\begin{array}{c}\begin{array}{c}\text { No. of } \\
\text { Comparisons }\end{array} \\
14 t, 8\end{array}$} & \multicolumn{4}{|c|}{ Comet-Star } & \multicolumn{6}{|c|}{ Comet's Apparent } & \multicolumn{2}{|c|}{$\log p \Delta$} \\
\hline & & & & & & & & $\Delta a$ & & $\delta$ & & $a$ & & & $\delta$ & & $a$ & $\delta$ \\
\hline June & 21 & $10^{\mathrm{h}}$ & $23^{\mathrm{m}}$ & $13^{\mathrm{s}}$ & & & $-1^{m}$ & $39 \$ 93$ & $-9^{\prime}$ & $38^{\prime \prime} .2$ & $12^{\mathrm{h}}$ & $53^{m}$ & $49 \$ 80$ & $+55^{\circ}$ & $02^{\prime}$ & $14^{\prime \prime} 2$ & 9.810 & $n 9.667$ \\
\hline July & 8 & 8 & 41 & 10 & 2 & $8 d, 8$ & + & 20.85 & -2 & 27.4 & 12 & 29 & 20.24 & +51 & 43 & 58.8 & 9.760 & $n 9.436$ \\
\hline & 9 & 11 & 25 & 26 & 3 & $12 d, 8$ & - & 19.49 & -7 & 19.9 & 12 & 28 & 16.80 & +51 & 31 & 05.7 & 9.875 & 0.544 \\
\hline & 13 & 9 & 04 & 01 & 4 & $10 d, 8$ & + & 38.71 & -4 & 00.8 & 12 & 25 & 01.37 & +50 & 46 & 46.3 & 9.812 & 9.880 \\
\hline & 19 & 8 & 45 & 10 & 5 & $10 d, 8$ & + & 49.52 & + & 48.7 & 12 & 21 & 09.94 & +49 & 41 & 20.5 & 9.810 & 0.023 \\
\hline & 25 & 8 & 47 & 54 & 6 & $12 d, 8$ & + & 8.00 & -6 & 12.2 & 12 & 18 & 30.07 & +48 & 39 & 32.3 & 9.825 & 0.250 \\
\hline & 31 & 8 & 48 & 17 & 7 & $10 d, 8$ & - & 24.26 & -1 & 04.3 & 12 & 16 & 49.65 & +47 & 41 & 56.3 & 9.831 & 0.385 \\
\hline August & 11 & 9 & 37 & 01 & $9 a$ & $12 d, 8$ & - & 32.21 & +4 & 52.4 & 12 & 15 & 46.78 & +46 & 07 & 48.2 & 9.821 & 0.663 \\
\hline & 12 & 8 & 15 & 37 & $9 b$ & $10 d, 8$ & - & 31.36 & -2 & 26.9 & 12 & 15 & 47.61 & +46 & 00 & 28.8 & 8.822 & 0.464 \\
\hline & 26 & 8 & 09 & 43 & 10 & $10 d, 6$ & - & 43.40 & +5 & 57.1 & 12 & 17 & 21.94 & +44 & 26 & 25.0 & 9.815 & 0.608 \\
\hline Septemk & 4 & 7 & 33 & 30 & 11 & $14 d, 14$ & - & 15.01 & +3 & 22.6 & 12 & 19 & 25.87 & +43 & 40 & 34.0 & 9.810 & 0.606 \\
\hline
\end{tabular}

Mean Places of Comparison Stars for 1904.0.

\begin{tabular}{cccc} 
Star & \multicolumn{3}{c}{$a$} \\
1 & $12^{\mathrm{h}}$ & $55^{\mathrm{m}}$ & 28596 \\
2 & 12 & 28 & 59.13 \\
3 & 12 & 28 & 36.07 \\
4 & 12 & 24 & 22.50 \\
5 & 12 & 20 & 20.37 \\
6 & 12 & 18 & 22.10 \\
7 & 12 & 17 & 14.00 \\
8 & 12 & 17 & 01.53 \\
$9 a$ & 12 & 16 & 19.16 \\
$9 b$ & 12 & 16 & 19.16 \\
10 & 12 & 18 & 05.60 \\
11 & 12 & 19 & 41.18
\end{tabular}

Red. to
App. place
+0577
+0.26
+0.22
+0.16
+0.05
-0.03
-0.09
-0.17
-0.17
-0.19
-0.26
-0.30

$\begin{array}{cccc} & \delta & & \begin{array}{c}\text { Red. to } \\ \text { App. place }\end{array} \\ +55^{\circ} & 11^{\prime} & 42^{\prime \prime} .0 & +10^{\prime \prime} 4 \\ +51 & 46 & 17.2 & +9.0 \\ +51 & 38 & 16.8 & +8.8 \\ +50 & 50 & 38.9 & +8.2 \\ +49 & 40 & 24.4 & +7.4 \\ +48 & 45 & 38.0 & +6.5 \\ +47 & 42 & 55.0 & +5.6 \\ +45 & 59 & 48.1 & +3.8 \\ +46 & 02 & 52.1 & +3.7 \\ +46 & 02 & 52.1 & +3.6 \\ +44 & 20 & 26.8 & +1.1 \\ +43 & 37 & 12.4 & -1.0\end{array}$
e

January $17,1905$.

J. D. MADDRILL.

* The comet is still visible in the 12 -inch telescope. An observation secured on January 26th shows that Nijland's ephemeris (Ephemeriden-Zirkular der Astron. Nach., 1904, Nr. 115) is very nearly exact.-R. G. AITKEN.

† Star 9-star 8: $\Delta a-42834 ; \Delta \delta+3^{\prime} 03^{\prime \prime} .7$. 